Revista Brasileira de Agricultura Irrigada v.6, nº 3, p. 184 - 197, 2012

ISSN 1982-7679 (On-line)

Fortaleza, CE, INOVAGRI - http://www.inovagri.org.br

DOI: $10.7127 /$ rbai.v6n300083

Protocolo 083.12 - 23/04/2012 Aprovado em 10/09/2012

\title{
ECONOMIA DE ENERGIA EM IRRIGAÇÃO POR PIVÔ CENTRAL EM FUNÇÃO DA MELHORIA NA UNIFORMIDẢDE DA DISTRIBUIÇÃO DE ÁGUA
}

\author{
Mendoza, C.J.C ${ }^{1}$, Frizzone, J.A ${ }^{2}$
}

\section{RESUMO}

Em sistemas de irrigação por pivô central, a eficiência de aplicação em campo esta diretamente relacionada com a uniformidade de distribuição, influindo assim na economia de energia, num manejo adequado da irrigação. No presente trabalho foram utilizados dados de lâmina aplicada, lâmina média, vazão e comprimento de um pivô central, da região de Guaíra-SP, determinados por IDE (1989) através de uma avaliação de desempenho, para analisar as variações nos benefícios econômicos, decorrentes da irrigação por pivô central, considerando as produtividades alcançadas com diferentes uniformidades de distribuição de água e os gastos com energia. Mediante simulações das lâminas coletadas conseguiram-se valores de 70, 75, 80, 85, 90, 95 e $98 \%$ do coeficiente de uniformidade de Christiansen (CUC), mas mantendo constante o valor da lâmina média e consequentemente a mesma vazão. Essas simulações de uniformidade de aplicação da água, do pivô central, foram comparadas utilizando-se sete preços do feijão: $\mathrm{R} \$ 1,75, \mathrm{R} \$ 2,00, \mathrm{R} \$ 2,25, \mathrm{R} \$ 2,50, \mathrm{R} \$ 2,75$, $\mathrm{R} \$ 3,00$ e $\mathrm{R} \$ 3,25 / \mathrm{kg}$, e de igual forma para cinco custos por consumo da água: $\mathrm{R} \$ 0,01$, $\mathrm{R} \$ 0,02, \mathrm{R} \$ 0,03, \mathrm{R} \$ 0,04$, e $\mathrm{R} \$ 0,05 / \mathrm{m}^{3}$. A partir dos dados obtidos nas simulações verificouse que o coeficiente de uniformidade apresenta maior sensibilidade no rendimento na cultura quando se tem os CUC-'s e os preços do produto maiores, assim como que o produtor terá maior lucro, correspondente com as simulações realizadas no período úmido do ano.

Palavras - chave: Coeficiente de uniformidade; Simulação; Receita liquida.

\section{ENERGY ECONOMY IN A CENTER PIVOT IRRIGATION SYSTEM ACCORDING TO THE IMPROVEMENT IN THE UNIFORMITY OF WATER DISTRIBUTION}

\begin{abstract}
In irrigation systems by center pivot, the efficiency of applying in field is directly related to distribution uniformity, influencing in energy saving inside an appropriate irrigation management program. Were used data from applied layer, average layer, flow and length of center pivot, from Guairá-SP, determined by IDE (1989) by a performance assessment, to analyze the variations in the economic benefits arising from the irrigation by central pivot, considering the yields achieved with different uniformity of water distribution and energy costs. By simulation of collected layers values of 70, 75, 80, 85, 90, 95 and 98\% were obtained from the Christiansen (CUC) Uniformity Coefficiency, keeping constant the
\end{abstract}

\footnotetext{
${ }^{1}$ Engenheiro Agrícola. Ms.C. Doutorando em Irrigação e Drenagem, ESALQ/USP, Piracicaba, SP, e-mail: christianmendozac@gmail.com

${ }^{2}$ Prof. Doutor, Depto de Engenharia de Biossistemas, ESALQ/USP, Piracicaba, SP
} 


\section{ECONOMIA DE ENERGIA EM IRRIGAÇÃO POR PIVÔ CENTRAL EM FUNÇÃO DA MELHORIA NA UNIFORMIDADE DA DISTRIBUIÇÃO DE ÁGUA}

average layer value and consequently the same flow. The obtained net income from those water distributions were compared using five beans prices in Brazilian currency 1,75, 2,00, $2,25,2,50,2,75,3,00$ and $\mathrm{R} \$ 3,25 \cdot \mathrm{kg}^{-1}$ and the same way, for five water consume costs: 0,01 , $0,02,0,03,0,04$, and $\mathrm{R} \$ 0,05 \cdot \mathrm{m}^{-3}$. From obtained data by simulations were verified that the higher uniformity coefficiencies give higher liquid recipe and greater energy saving related to higher products prices, of higher profit and greater energy saving especially when made in the humid season

Keyword: Coefficient of uniformity, simulation, net income.

\section{INTRODUÇÃO}

No Brasil, atualmente existem soluções técnicas para o problema de escassez da água as quais implicam na adoção de novas políticas no uso do recurso hídrico; como a recente aprovação da cobrança pelo uso da água, os produtores rurais irrigantes deverão priorizar a utilização precisa da água a ser aplicada em cada operação, por isso, busca-se maior ênfase na adoção de soluções técnicas, que vão desde a melhoria na condução da água em projetos de irrigação, até o aumento de eficiência de aplicação nas parcelas, que depende da uniformidade de distribuição da água, para isto necessita se de investimentos em pesquisas visando o melhor aproveitamento do recurso.

Em sistemas de irrigação por pivô central, a eficiência de aplicação em campo esta diretamente relacionada com a uniformidade de distribuição, que mede a variação espacial da precipitação, normalmente representada pelo coeficiente de uniformidade, de Christiansen, (1942), CUC, modificado por Hermann \& Hein. (1968), geralmente a uniformidade de distribuição é o principal critério utilizado para avaliar adequação de um sistema de irrigação. Tarjuelo et al. (1996) salientam que os benefícios econômicos da irrigação aumentam em função do aumento da uniformidade de distribuição, independentemente do custo da água. Marek et al. (1986), compararam o CUC com o coeficiente de variação (CV), e concluíram que o $\mathrm{CV}$ é mais adequado para comparações de sistemas de irrigação pivô central, entre tanto, o CUC foi consagrado pelo uso ao longo dos anos.

A uniformidade de aplicação de água, utilizada como um dos principais parâmetros para avaliar o desempenho de um sistema de irrigação, é afetada por vários fatores: diâmetro da tubulação lateral, diâmetro dos bocais, espaçamento entre emissores, altura do pendural, característica operacional dos reguladores de pressão, velocidade do vento e uniformidade topográfica do terreno, Os cinco primeiros fatores são essencialmente hidráulicos característicos do equipamento, podendo ser previsto no projeto do sistema (Frizzone \& Dourado Neto, 2003). A velocidade do vento é um fator climático que deve ser previsto durante a operação e a topografia do terreno é um fator local também previsível em projeto.

Nos sistemas de irrigação por pivô central utilizam se válvulas reguladoras de pressão para minimizar os efeitos da variação de pressão na vazão dos emissores, permitindo uma pressão de saída aproximadamente constante em um intervalo de pressão de entrada. Estas válvulas reguladoras diminuem sua capacidade de regulação, por dimensionamento inadequado da linha lateral ou por desgaste pelo uso, necessitando se aumentar a lâmina aplicada para compensar o efeito da falta de uniformidade na produção ou alternativamente trocar o conjunto de aspersão (válvula reguladora de pressão e emissor). 


\section{ECONOMIA DE ENERGIA EM IRRIGAÇÃO POR PIVÔ CENTRAL EM FUNÇÃO} DA MELHORIA NA UNIFORMIDẢDE DA DISTRIBUIÇÃO DE ÁGUA

O objetivo deste trabalho é analisar as variações nos benefícios econômicos decorrentes da irrigação por pivô central na cultura do feijoeiro considerando as produtividades alcançadas com diferentes uniformidades de distribuição de água e os

\section{MATERIAL E MÉTODOS}

Este trabalho foi desenvolvido com a linguagem de programação Visual Basic, usando como base o programa de Excel e seus Macros. Essa linguagem foi selecionada pela simplicidade de programação e principalmente, pela facilidade de se fazerem atualizações futuras nas suas rotinas.

Inicialmente foi realizada a programação dos Macros para determinar o valor do coeficiente de uniformidade nos valores de 70, 75, 80, 85, 90\%, 95 e 98\%, isto, simulando as lâminas da água coletadas no teste de desempenho do pivô, o que foi conseguido utilizando-se $o$ Solver do programa Excel, tendo como restrições o valor da lâmina média aplicada $(10,4 \mathrm{~mm})$ e os valores máximos e mínimos das lâminas medias coletadas no teste de desempenho, 4,0 $\mathrm{mm}$ e 13,4 $\mathrm{mm}$, respectivamente, e como célula objetivo o valor desejado a atingir do CUC.

Após das simulações realizou-se o cálculo do rendimento da cultura com a função de produção obtida por Saad (1996). Com os dados de rendimento determinaram-se as receitas brutas para cada um dos preços avaliados do feijoeiro.

Seguidamente foi realizado o cálculo dos custos por consumo de energia e por consumo da água, para determinar os valores da receita líquida para cada um dos coeficientes de uniformidade avaliados.

\section{Características do pivô avaliado}

Neste trabalho utilizou-se como base um sistema pivô central da região de Guaíra (SP), descrito por IDE (1989), gastos com energia, mantendo-se a lâmina media aplicada nas diferentes uniformidades. A redução da receita liquida é comparada com o custo do conjunto de aspersão (reguladores de pressão mais emissores) para definir a viabilidade da troca desse conjunto.

cujas características de projeto são apresentadas a seguir:

Velocidade Deslocamento da ultima torre a 50\%: $80,4 \mathrm{~m} \mathrm{~h}^{-1}$

Velocidade Máxima da Última Torre (100\%): 160,8 $\mathrm{m} \mathrm{h}^{-1}$

Propriedade: Fazenda Santa Helena Guaíra-SP

Comprimento da Lateral: 613,9 m

Número de Torres: 13

Distância entre torres: $46,3 \mathrm{~m}$

Comprimento do Balanço: $12 \mathrm{~m}$

Alcance do Canhão Final: Não possui

Raio Efetivo da Área Irrigada $\left(\mathrm{R}_{\mathrm{T}}\right): 619,9$ $\mathrm{m}$

Comprimento da linha lateral $\left(\mathrm{R}_{\mathrm{L}}\right): 46,3 \mathrm{x}$ $13+12=613,9 \mathrm{~m}$

Comprimento até a ultima torre $\left(\mathrm{R}_{\mathrm{U}}\right)=46,3$ $\mathrm{x} 13=601,9 \mathrm{~m}$

Raio de área básica irrigada $\left(\mathrm{R}_{\mathrm{b}}\right)=613,9+$ $5=618,9 \mathrm{~m}$

Área irrigada (A): 120,3 ha

Potencia do Conjunto motobomba $=250$

CV

Vazão: $316 \mathrm{~m}^{3} \mathrm{~h}^{-1}$

Diâmetro do Coletor: $82 \mathrm{~mm}$

Área do Coletor: $5278,34 \mathrm{~mm}^{2}$

Para este pivô central IDE (1989) apresenta um ensaio de uniformidade de aplicação da água, utilizando-se duas linhas de coletores defasadas de $3^{\circ}$, com coletores espaçados de $5,5 \mathrm{~m}$.

\section{Cálculo do Coeficiente de Uniformidade}

Para o cálculo do coeficiente de uniformidade de aplicação de água pelo sistema pivô central foram adotadas as seguintes equações:

Coeficiente de Uniformidade de Christiansen (1942) modificado por Heermann e Hein (1968) 


\section{ECONOMIA DE ENERGIA EM IRRIGAÇÃO POR PIVÔ CENTRAL EM FUNÇÃO} DA MELHORIA NA UNIFORMIDẢDE DA DISTRIBUIÇÃO DE ÁGUA

$$
C U C=100\left[1-\frac{\sum_{i=1}^{N} S_{i}\left|X_{i}-\frac{\sum X_{i} S_{i}}{\sum} S_{i}\right|}{\sum X_{i} S_{i}}\right]
$$

em que:

CUC - coeficiente de uniformidade, $\%$

$X_{i}$ - lâmina de água coletada, mm

$S_{i}$ - distância do coletor i ao ponto do pivô, $m$

$$
\bar{X}_{p}=\frac{\sum X_{i} S_{i}}{\sum S_{i}}
$$

\section{Função de produção da cultura irrigada} A cultura utilizada neste trabalho foi o feijoeiro, cuja função de produção (Figura
(1)

$\mathrm{Na}$ Eq. (1) utiliza-se a lâmina media ponderada $\bar{X}_{p}$ para o cálculo de CUC, expressa pela seguinte equação:

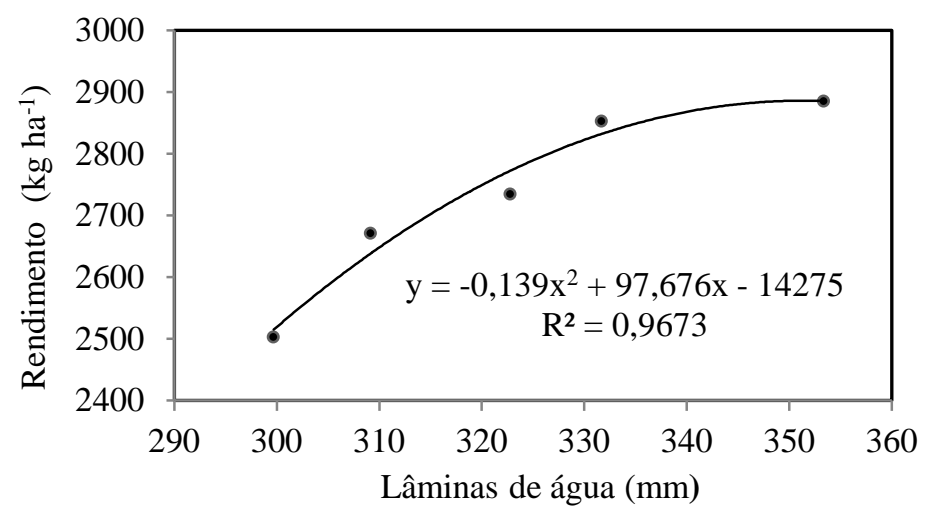

Figura 1 - Função de produção do feijoeiro para a região de Guaíra (SP), Saad (1996).

\section{Receitas da cultura irrigada}

Para o cálculo da receita bruta utilizaram-se sete preços para o produto, $\mathrm{R} \$ 1,75, \mathrm{R} \$ 2,00, \mathrm{R} \$ 2,25, \mathrm{R} \$ 2,50, \mathrm{R} \$ 2,75$, $\mathrm{R} \$ 3,00$ e $\mathrm{R} \$ 3,25 / \mathrm{kg}$, baseados na variação do preço do produto pesquisados para a região de São Paulo no período de maio a setembro de 2009 (PROCON - SP), e assim, multiplicado pelos rendimentos.

Para obter as margens brutas, ou receita liquida operacional (receita bruta menos custos operacionais) foram utilizados os gastos com energia e água. $\mathrm{Na}$ estimativa dos custos de água foram considerados os custos por consumo ( $\mathrm{R} \$$ $0,01 / \mathrm{m}^{3}$ até $\left.\mathrm{R} \$ 0,05 / \mathrm{m}^{3}\right)$, valores da cobrança pelo uso da água, desde o valor atual na bacia PCJ e valores futuros com aumento progressivo (MARTINEZ Jr e LAHOZ, 2007).

$\mathrm{O}$ custo de energia foi estimado tendo como base a tarifa Verde, do subgrupo A4 (2,3 a $25 \mathrm{~kW})$. Nesse subgrupo as tarifas se dividem em: (a) tarifa por demanda: $\mathrm{R} \$ 4,67$ por $\mathrm{kW}$, aplicado o mesmo valor para o horário de ponta e horário fora de ponta; e (b) tarifa por consumo: $\mathrm{R} \$ 416,3$ por MWh para o período seco em horário de ponta; $\mathrm{R} \$$ 43,74 por MWh para o período seco em horário fora de ponta; para o período úmido os custos por consumo em período 


\section{ECONOMIA DE ENERGIA EM IRRIGAÇÃO POR PIVÔ CENTRAL EM FUNÇÃO DA MELHORIA NA UNIFORMIDẢDE DA DISTRIBUIÇÃO DE ÁGUA}

de ponta e fora de ponta são $\mathrm{R} \$ 409,47$ e $\mathrm{R} \$ 38,66$ por $\mathrm{MWh}$, respectivamente e; (c) tarifa por ultrapassagem tendo o valor para o horário de ponta e fora de ponta de $\mathrm{R} \$ 14,04$ por $\mathrm{kW}$. Segundo Souza (2001) pode-se optar por desconsiderar as tarifas de ultrapassagem de carga nos cálculos de custo de energia, porque os motores elétricos utilizados em projetos de

$$
C A B=(F D a-F C a) \cdot\left(\frac{0,92}{\cos \varphi}\right) \cdot(1+I C M S)
$$

em que:

Cab: Custo anual do bombeamento, ( $\mathrm{R} \$$ ha $^{-1}$ ano $^{-1}$ )

FCa: Faturamento anual do consumo, $(\mathrm{R} \$$ ha $^{-1}$ ano $^{-1}$ )

FDa: Faturamento anual da demanda, ( $\mathrm{R} \$$ ha $^{-1}$ ano $^{-1}$ )

ICMS: Imposto sobre circulação de mercadorias e serviços cobrados na região, (decimal)

$$
D=0,736 \cdot P o t
$$

em que:

D: demanda contratada $\left(\mathrm{kW} \mathrm{ha}^{-1}\right)$

Pot: potência do motor (cv ha $\left.{ }^{-1}\right)$

A simulação foi realizada para cada

um dos valores dos coeficientes de uniformidade, descritos anteriormente, variando a lâmina média de água aplicada por cada setor do pivô (lâmina coletada),

\section{RESULTADOS E DISCUSSÃO}

A Figura 2 apresenta o perfil de distribuição de água inicial do pivô central utilizado para realizar este trabalho, irrigação são em número reduzidos e basicamente exclusivos para realizar o acionamento de bombas hidráulicas e equipamentos destinados à movimentação do sistema de irrigação.

O custo anual de bombeamento foi obtido pela Eq. (3) desenvolvida por Marques (2005), considerando o motor elétrico.

$\cos \varphi$ : fator de potência

Para o cálculo anual de bombeamento primeiro foi calculado o faturamento mensal da demanda obtido pela Eq. (4), sendo que os meses em que não há necessidade de irrigar existe a cobrança de $10 \%$ do valor da demanda (SOUZA, 2001; ZOOCOLER, 2003).

porém, mantendo-se a lâmina média aplicada na área total irrigada. Este procedimento foi feito utilizando-se Solver do Excel, fazendo-se variar cada uma das lâminas aplicadas aleatoriamente até atingir um valor prefixado de coeficiente de uniformidade.

conforme apresenta IDE (1989). Para esta distribuição obteve-se lâmina média aplicada de 10,4 $\mathrm{mm}$ e coeficiente de uniformidade de Christiansen (CUC) igual a $88,2 \%$. 
ECONOMIA DE ENERGIA EM IRRIGAÇÃO POR PIVÔ CENTRAL EM FUNÇÃO DA MELHORIA NA UNIFORMIDẢDE DA DISTRIBUIÇÃO DE ÁGUA

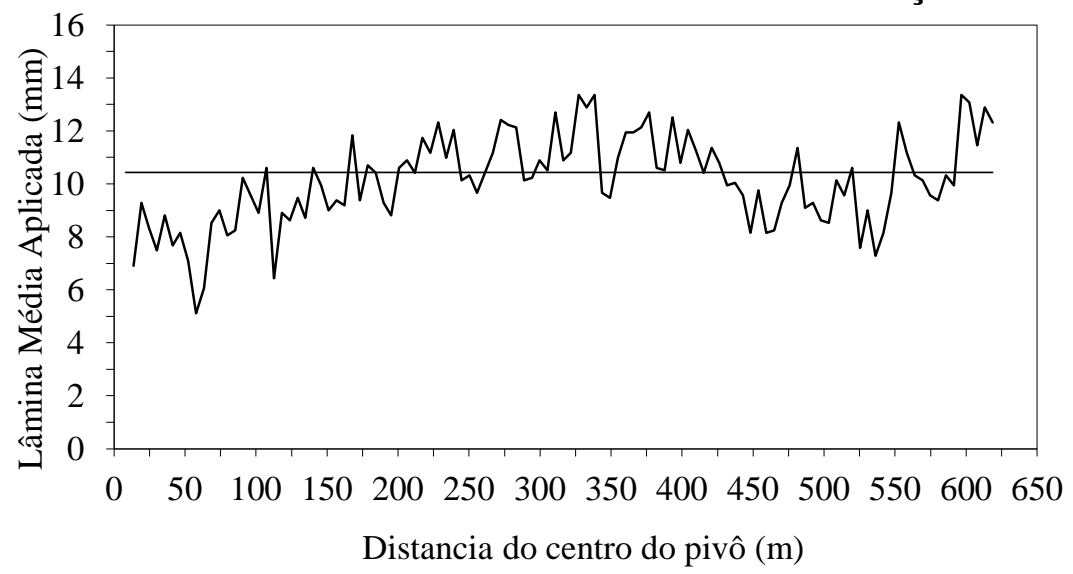

Figura 2 - Perfil de aplicação de água pelo sistema pivô central

Foram simuladas sete distribuições de água com CUC-'s de 70, 75, 80, 85, 90, 95 e $98 \%$. Com estas distribuições foram estimadas produtividades, receitas brutas e receitas líquidas, utilizando sete preços do

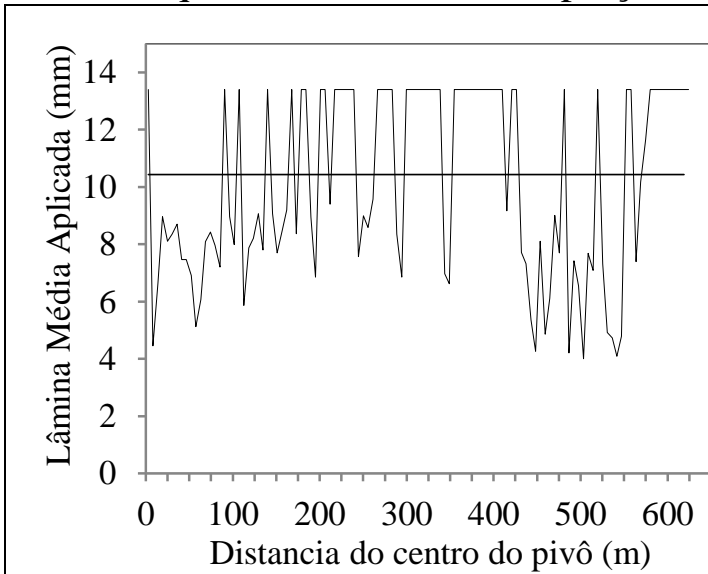

(a)

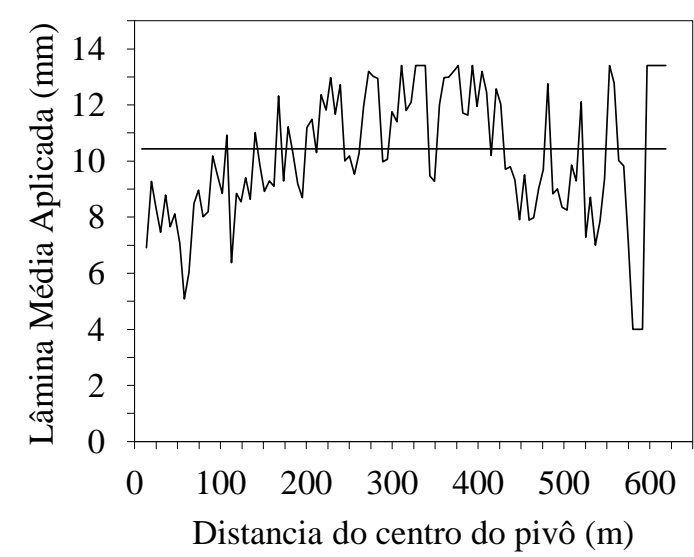

(c) produto, variando de $\mathrm{R} \$ 1,75 / \mathrm{kg}$ a $\mathrm{R} \$ 3,25 / \mathrm{kg}$. Nas Figuras 3a a 3I são apresentadas as distribuições de água simuladas para os diferentes CUC-'s.

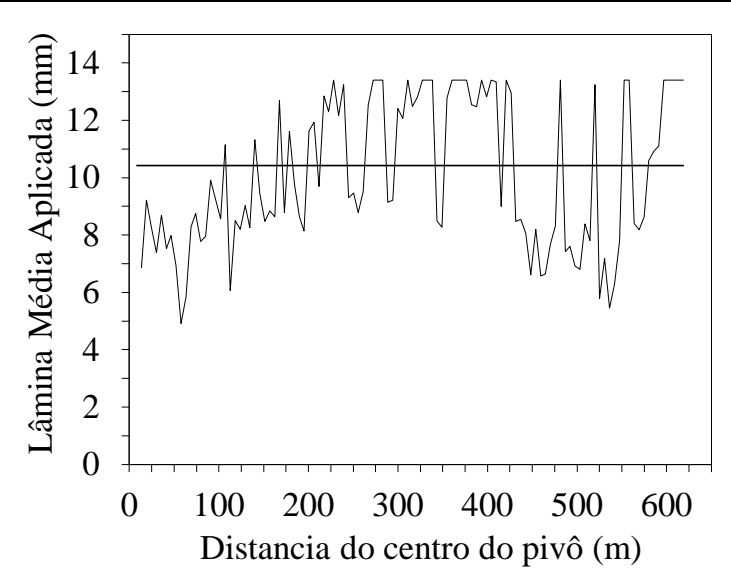

(b)

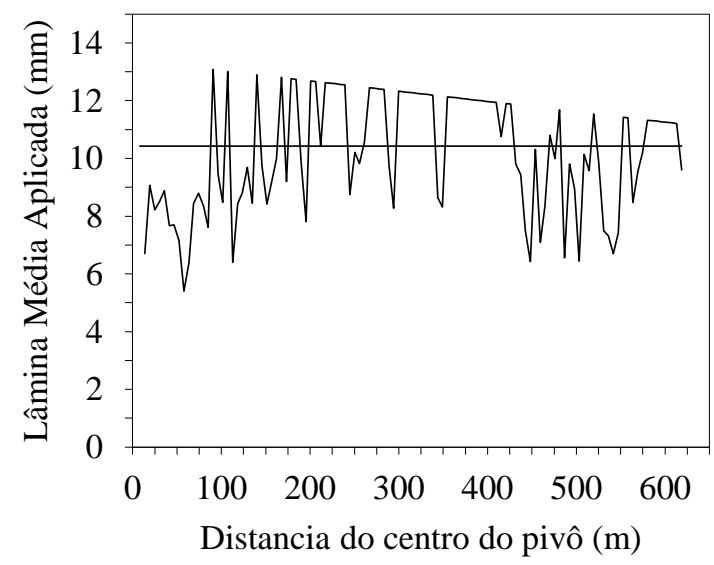

(d) 
ECONOMIA DE ENERGIA EM IRRIGAÇÃO POR PIVÔ CENTRAL EM FUNÇÃO DA MELHORIA NA UNIFORMIDẢDE DA DISTRIBUIÇÃO DE ÁGUA

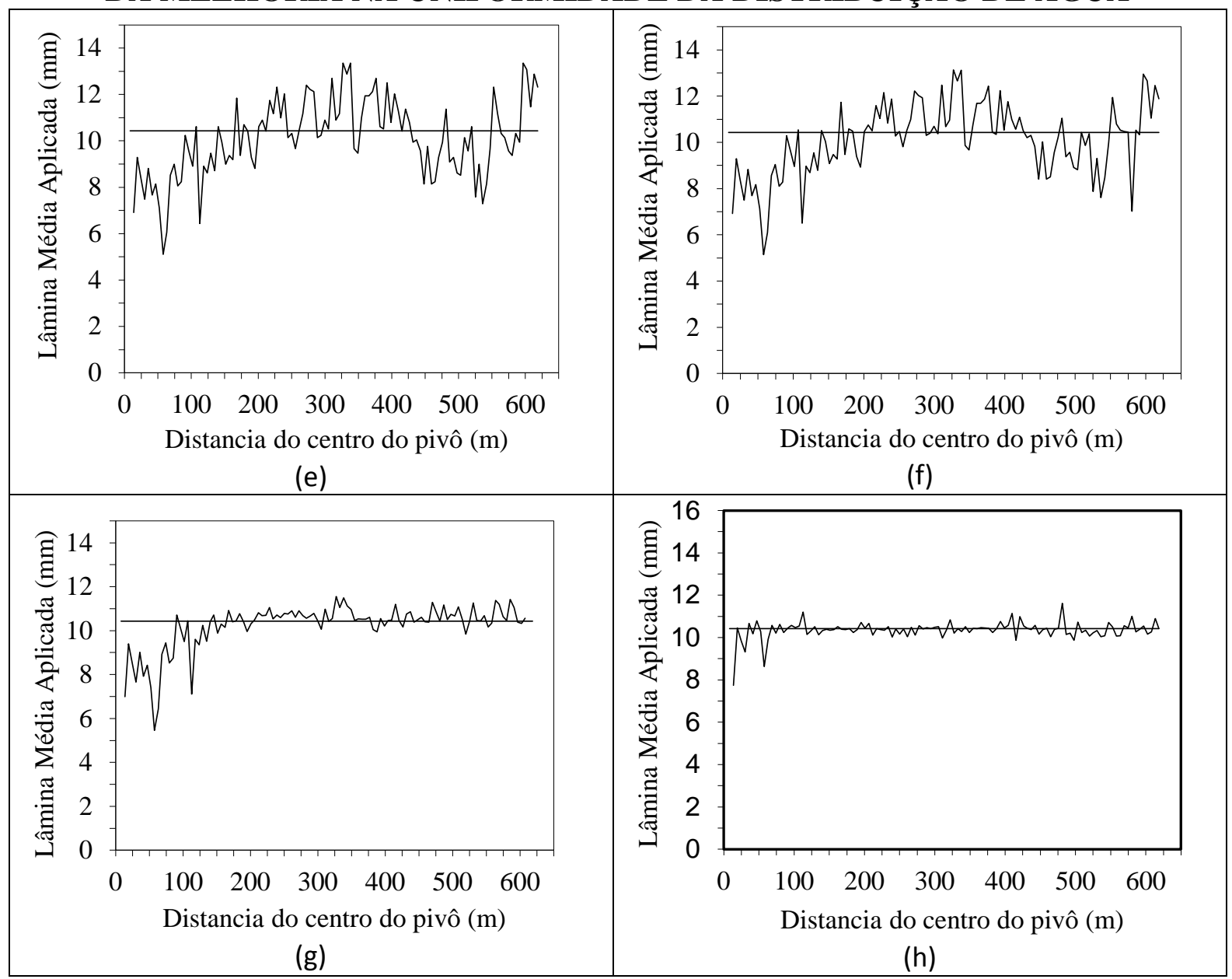

Figura 3 - Simulação das distribuições de água pelo pivô central com CUC-'s variando de 70\% a $98 \%$ e lâmina media de $10,4 \mathrm{~mm}$

Nas simulações feitas na Figura 3, para os CUC-'s de; (a) 70\%, (b) 75\%, (c) $80 \%$, (d) $85 \%$, (e) $88,2 \%$ (f) $90 \%$ (g) $95 \%$ e (h) $98 \%$ observa-se que se consegue um coeficiente de uniformidade maior para aplicação de água mais uniforme no final da linha do pivô. Porem, observa-se, para os CUC-'s abaixo de $90 \%$, que existe uma sequência alternada de excesso e déficit de aplicação de área ocorrendo a intervalos de distância aproximadamente regulares, que no entanto, são bem maiores que o espaçamento médio entre as saídas.

Observa-se que nos CUC-'s abaixo do valor representativo da distribuição de água do pivô, com os dados do ensaio experimental, inviabilizando, assim, uma boa uniformidade de aplicação de água.

Portanto, o conhecimento do desempenho do equipamento, principalmente em relação à uniformidade de distribuição de água e lâmina de água aplicada, é imprescindível para se tomar medidas que permitam economizar água e energia. Quando se aplica somente a lâmina de irrigação necessária numa área (sendo que esta lâmina corresponde à lâmina média), devido à falta de uniformidade, uma fração dessa área é irrigada com excesso, enquanto que em outra fração ocorre déficit de água. $\mathrm{Na}$ fração com excesso, uma parte fica armazenada na zona das raízes para uso das plantas e a outra parte é perdida por percolação profunda, transportando também parte dos nutrientes daquela camada. Na fração com déficit, toda água infiltrada é considera armazenada na zona radicular, porém, em quantidade inferior às necessidades hídricas das plantas. 
ECONOMIA DE ENERGIA EM IRRIGAÇÃO POR PIVÔ CENTRAL EM FUNÇÃO DA MELHORIA NA UNIFORMIDẢDE DA DISTRIBUIÇÃO DE ÁGUA

Variação do rendimento da cultura do feijoeiro e da receita bruta em função de diferentes coeficientes de uniformidade para irrigação total

$y=-0,139 \cdot x^{2}+97,676 \cdot x-14275$

A Figura 4 apresenta a curva de rendimento médio do feijoeiro para cada um dos coeficientes de uniformidade avaliados, supondo que toda água

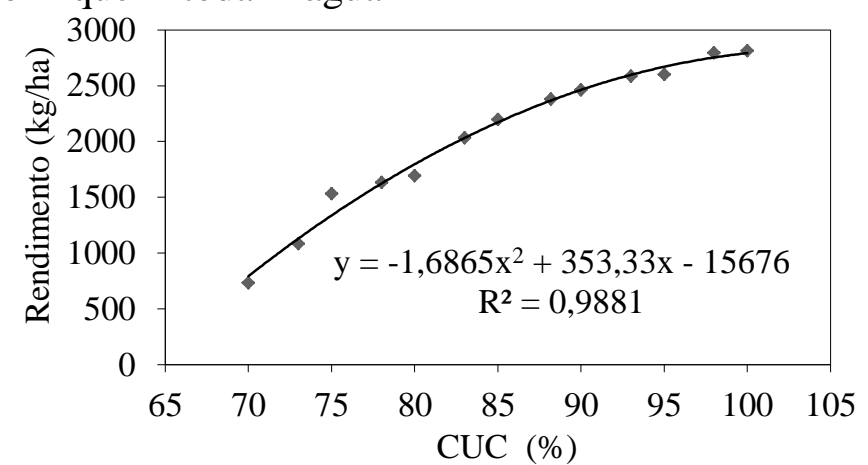

Figura 4 - Rendimento médio do feijoeiro calculado para diferentes valores de uniformidade de distribuição de água (CUC)

Depois de serem realizados os cálculos dos rendimentos médios em função dos coeficientes de uniformidade, foram calculadas as receitas brutas resultantes da irrigação do feijoeiro, para irrigação total, para diferentes preços do

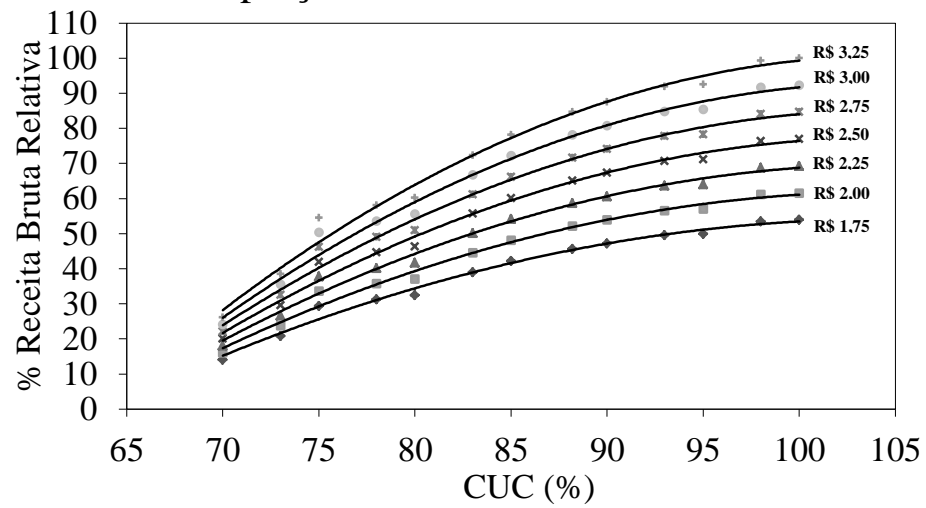

Figura 5 - Receita Bruta Relativa (\%) calculada para os sete preços do produto para os diferentes Coeficientes de Uniformidade de Christiansen (CUC) avaliados

Um resumo dos principais resultados de receita bruta, em três valores de CUC, é apresentado na Tabela 1. Os valores de receita bruta crescem com o aumento da uniformidade, uma vez que se obtêm maiores rendimentos de grãos. $\mathrm{O}$ produto. Na Figura 5 apresentam-se os valores relativos de receitas brutas possíveis de serem obtidos com preços do feijão variando de $R \$ 1,75$ a $R \$ 3,25$ por quilo. necessária
irrigação. cada um dos diferentes coeficientes de partir da função de produção expressa pela Eq. (5), desenvolvida por Saad (1996). 


\section{ECONOMIA DE ENERGIA EM IRRIGAÇÃO POR PIVÔ CENTRAL EM FUNÇÃO} DA MELHORIA NA UNIFORMIDẢDE DA DISTRIBUIÇÃO DE ÁGUA

menor valor de receita bruta, o que, dependendo dos custos da irrigação poderá proporcionar o menor valor de receita líquida. Verifica-se também que para valores de CUC menores, o preço do produto tem menor influência sobre a variação da receita bruta.

Tabela 1 - Valores de receita bruta para diferentes CUC-'s em cada um dos preços do produto avaliado

\begin{tabular}{cccc}
\hline \multirow{2}{*}{$\begin{array}{c}\text { Preço do } \\
\text { produto R\$/kg }\end{array}$} & \multicolumn{3}{c}{ Receita bruta máxima (R\$/ha) } \\
\cline { 2 - 4 } & CUC $=100 \%$ & CUC $=88,2 \%$ & CUC $=70 \%$ \\
\hline 3,25 & 9134,90 & 7731,50 & 2383,30 \\
3,00 & 8432,22 & 7136,77 & 2199,97 \\
2,75 & 7729,53 & 6542,04 & 2016,63 \\
2,50 & 7026,85 & 5947,31 & 1833,30 \\
2,25 & 6324,16 & 5352,58 & 1649,97 \\
2,00 & 5621,48 & 4757,85 & 1466,64 \\
1,75 & 4918,79 & 4163,12 & 1283,31 \\
\hline
\end{tabular}

Quando é comparada a receita bruta para o mesmo CUC, pode-se observar que, para o valor de CUC = $100 \%$, têm uma redução gradual de $7,69 \%$ para cada preço do produto avaliado. Por exemplo, a redução da receita para o preço de $\mathrm{R} \$ 3,00 / \mathrm{kg}$ em relação ao preço de $\mathrm{R} \$ 3,25 / \mathrm{kg}$ é de $7,69 \%$, e para o preço de
$\mathrm{R} \$ 2,75 / \mathrm{kg}$ a redução é de $15,38 \%$, alcançando assim, para o menor preço do feijão $(\mathrm{R} \$ 1,75 / \mathrm{kg})$, uma redução na receita bruta de $46,15 \%$.

Utilizando a área total irrigada pelo pivô central (120,3 ha), podem ser estimados os valores de receita bruta apresentados na Tabela 2.

Tabela 2 - Valores de receita bruta máxima para os 120,3 ha irrigados nos diferentes CUC-'s em cada um dos preços do produto

\begin{tabular}{cccc}
\hline \multirow{2}{*}{$\begin{array}{c}\text { Preço do } \\
\text { produto } \\
\mathrm{R} \$ / \mathrm{kg}\end{array}$} & \multicolumn{3}{c}{ Receita bruta máxima para a área total do pivô $(\mathrm{R} \$)$} \\
\cline { 2 - 4 } & CUC $=100 \%$ & CUC $=88,2 \%$ & CUC $=70 \%$ \\
\hline 3,25 & $1.098 .928,47$ & $930.099,45$ & $286.710,99$ \\
3,00 & $1.014 .396,07$ & $858.553,43$ & $264.656,39$ \\
2,75 & $929.862,46$ & $787.007,41$ & $242.600,59$ \\
2,50 & $845.330,06$ & $715.461,39$ & $220.545,99$ \\
2,25 & $760.796,45$ & $643.915,37$ & $198.491,39$ \\
2,00 & $676.264,04$ & $572.369,36$ & $176.436,79$ \\
1,75 & $591.730,44$ & $500.823,34$ & $154.382,19$ \\
\hline
\end{tabular}

Ao comparar os valores totais da receita bruta (Tabela 2) para o mesmo preço do produto, mas variando o CUC de $100 \%$ para $88,2 \%$, pode-se observar que para o valor de $\mathrm{R} \$ 3,25 / \mathrm{kg}$, a receita bruta tem uma redução de $15,36 \%$, isto é, de $\mathrm{R} \$ 168.829,02$ no total da área irrigada pelo pivô. Se o CUC abaixa para $70 \%$, a redução atinge a porcentagem de $73,91 \%$, significando uma redução de
$\mathrm{R} \$ 812.217,48$. O que implica que com o aumento da uniformidade de distribuição

do pivô central o produtor teria um aumento na renda bruta de $\mathrm{R} \$ 1.403,4 / \mathrm{ha}$, esse aumento da renda ficaria ainda mais evidente quando se consegue uma melhoria na uniformidade de distribuição de água pelo pivô central de CUC $=70 \%$ para um CUC $=100 \%$, totalizando assim, 


\section{ECONOMIA DE ENERGIA EM IRRIGAÇÃO POR PIVÔ CENTRAL EM FUNÇÃO}

DA MELHORIA NA UNIFORMIDẢDE DA DISTRIBUIÇÃO DE ÁGUA

$\mathrm{R} \$ 3.635,48 /$ há de aumento da receita bruta, isto para o valor do preço mais baixo avaliado ( $\mathrm{R} \$ 1,75 / \mathrm{kg})$.

Quando avaliado o produto com o preço mais elevado ( $\mathrm{R} \$ 3,25 / \mathrm{kg})$, esse aumento da receita bruta, devido à melhoria na uniformidade de distribuição de água pelo pivô central de 70 para 90\%, atingiria o valor de $\mathrm{R} \$ 6.751,6 / \mathrm{ha}$.

Assim, se a lâmina média de irrigação aplicada for maior que a necessária, pode-se até eliminar a fração com déficit de irrigação, porém o custo da irrigação sobe, podendo até se tornar inviável economicamente, além de agravar a lixiviação dos nutrientes. Portanto, a uniformidade de distribuição da água da irrigação deve ser analisada não apenas como uma simples informação de

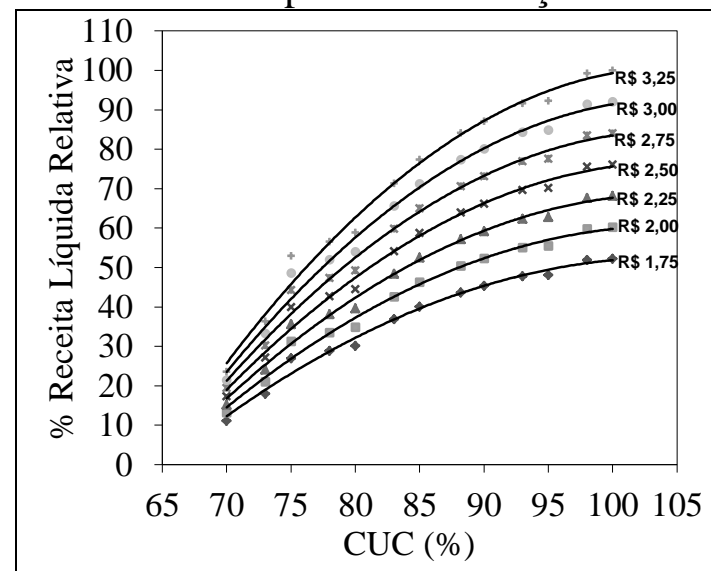

(a)

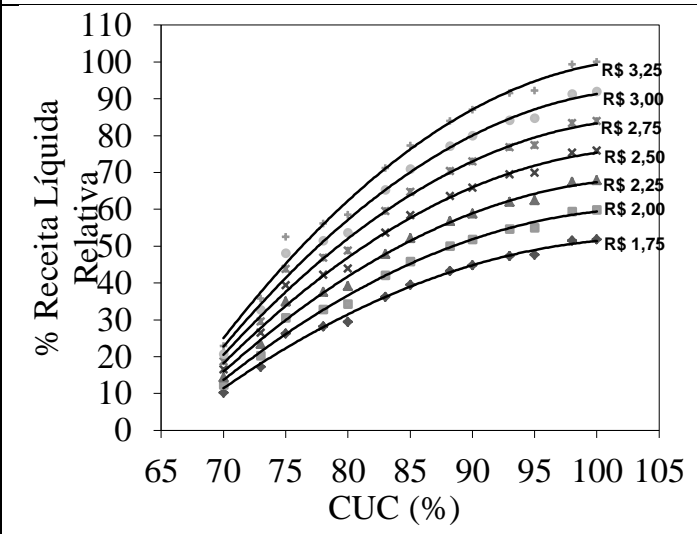

(c) dispersão, mas sim como um importante parâmetro na avaliação econômica da irrigação (ZOCOLER et al., 2004).

Influência da uniformidade de distribuição de água e do custo da água sobre a receita liquida para irrigação total

$\mathrm{Na}$ determinação da receita líquida foram avaliados cinco preços da água, apresentados nas Figuras 6 e 7, para as duas épocas do ano, períodos úmido e seco. Nas Figuras 6a a 6f são apresentadas as receitas líquidas em função dos CUC-'s, para os diferentes preços do produto e para os seis custos por consumo de água, sendo: (a) sem custo da água, (b) $\mathrm{R} \$ 0,01 / \mathrm{m}^{3}$, (c) $\mathrm{R} \$ 0,02 / \mathrm{m}^{3}$, (d) $\mathrm{R} \$ 0,03 / \mathrm{m}^{3}$, (e) $\mathrm{R} \$ 0,04 / \mathrm{m}^{3}$ e (f) $\mathrm{R} \$ 0,05 / \mathrm{m}^{3}$.

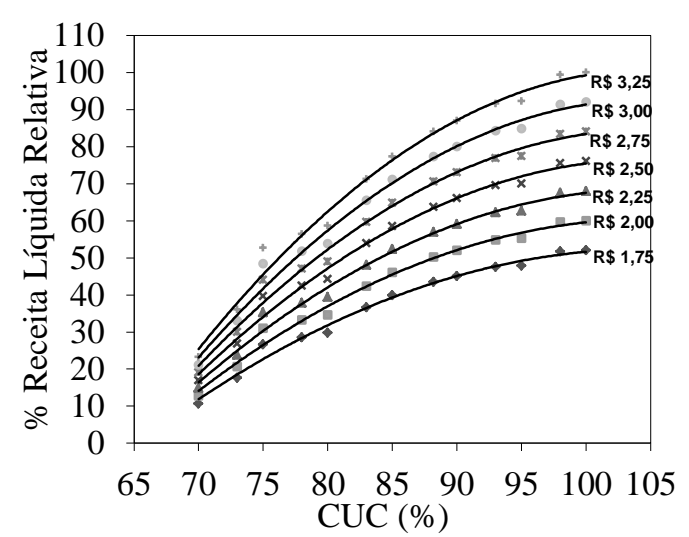

(b)

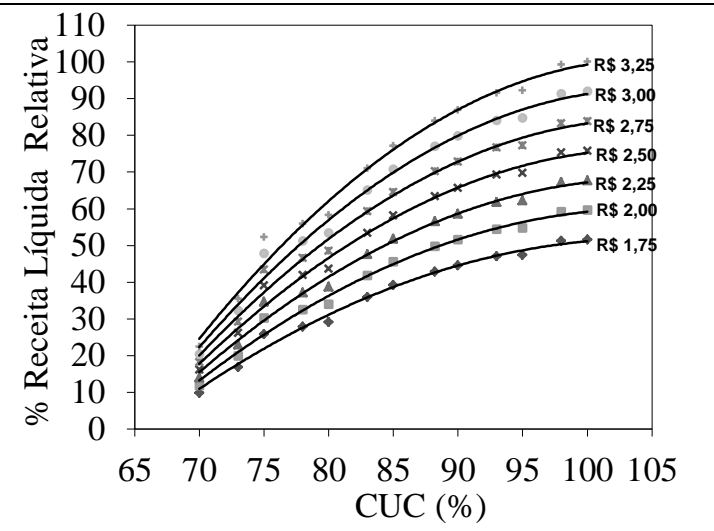

(d) 
ECONOMIA DE ENERGIA EM IRRIGAÇÃO POR PIVÔ CENTRAL EM FUNÇÃO DA MELHORIA NA UNIFORMIDẢDE DA DISTRIBUIÇÃO DE ÁGUA

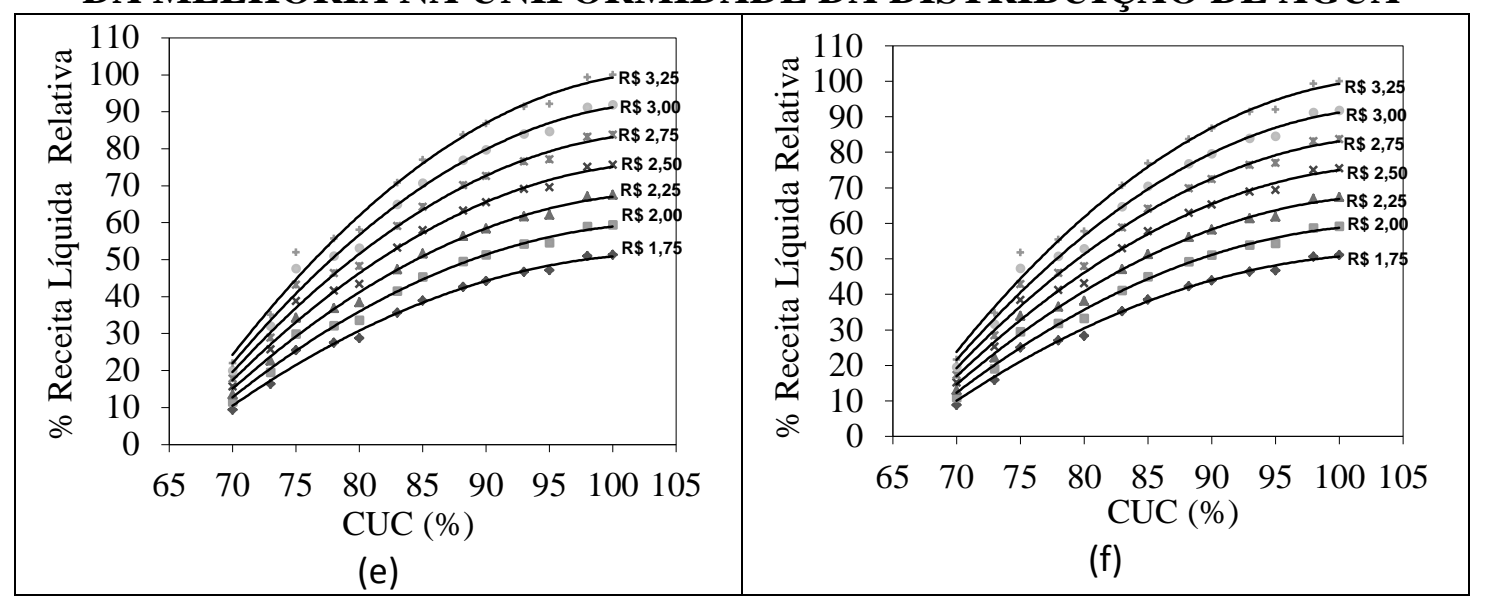

Figura 6 - Receita líquida relativa (\%) em função do Coeficiente de Uniformidade de Christiansen (CUC), no período seco, para seis preços da água.

Ao aumentar o valor da água de zero para $\mathrm{R} \$ 0,02 / \mathrm{m}^{3}$ (Figura $6 \mathrm{c}$ ) o valor da receita liquida, para o $\mathrm{CUC}=70 \%$, reduziu-se em $0,90 \%$ para o preço do feijão de $\mathrm{R} \$ 1,75 /$ ha, com relação ao valor da receita liquida quando não se tem custo por consumo da água. Em relação ao valor da receita liquida quando o custo da agua é de $\mathrm{R} \$ 0,01 / \mathrm{m}^{3}$ a redução da receita liquida foi $0,45 \%$. Para o maior preço do feijão ( $\mathrm{R} \$ 3,25 / \mathrm{ha})$, a redução da receita liquida é menor, sendo $0,49 \%$ mais baixa no mesmo CUC de $70 \%$, em relação à receita liquida quando não se tem custo por consumo de água. Em todos os casos, observa-se a redução da receita líquida com o aumento do custo da água por consumo, em todos os CUC-'s. Entretanto, o efeito do preço da água sobre a receita líquida é relativamente menor para maiores preços do produto e maiores CUC-'s.

Quando o CUC é igual a $90 \%$, ao aumentar o custo da água de zero para $\mathrm{R} \$ 0,02 / \mathrm{m}^{3}$ (Figura 6c), com preço do feijão de $\mathrm{R} \$ 1,75 / \mathrm{ha}$, o valor da receita liquida reduz em $0,56 \%$, significando uma redução de $\mathrm{R} \$ 88,89 / \mathrm{ha}$, o que para o total da área irrigada atinge $\mathrm{o}$ valor de R\$101.693/ha. Já para o mesmo CUC $(90 \%)$, mas para o preço do produto de $\mathrm{R} \$ 2,50 / \mathrm{ha}$, ao aumentar o custo da água de zero para $\mathrm{R} \$ 0,02 / \mathrm{m}^{3}$, a receita reduziu-se em $0,34 \%$, sendo por tanto, que a receita liquida tem uma redução menor pelo incremento no preço do produto, o que gera um ingresso maior mantendo-se o custo por consumo de energia, já que não se incrementa o tempo de irrigação unicamente a uniformidade de aplicação da água, se for melhorada pela manutenção do equipamento de irrigação ou pela troca do mesmo,se esta uniformidade for melhorada aumentando o tempo de irrigação esse valor da receita liquida será ainda menor por considerar o aumento do gasto com energia de bombeamento.

Na Figura 6(f), onde se observa a variação da receita líquida em função do CUC para o maior custo por consumo de água $\left(\mathrm{R} \$ 0,05 / \mathrm{m}^{3}\right)$, a redução máxima da receita liquida, em relação a quando não se tem custo por consumo da água, atinge o valor de 2,29\% para o CUC de $70 \%$. Para o CUC $=90 \%$, para os cinco preços do produto, a redução da receita liquida em relação a quando não se tem custo por consumo de água, é de $1,41 \%$ ( $\mathrm{R} \$ 1,75 / \mathrm{ha})$, $1,23 \% \quad(\mathrm{R} \$ 2,00 / \mathrm{ha}), 1,05 \% \quad(\mathrm{R} \$ 2,25 / \mathrm{ha})$, $0,87 \%$ (R $\$ 2,50 / \mathrm{ha}), 0,69 \%$ (R $\$ 2,75 / \mathrm{ha})$, $0,51 \%$ ( $\mathrm{R} \$ 3,00 / \mathrm{ha}$ ) e $0,33 \%$ ( $\mathrm{R} \$ 3,25 / \mathrm{ha}$ ), significando que a receita liquida, mantendo-se os custos por consumo de energia e por consumo da água, será mais afetada quando o custo do produto é menor.

Para o período úmido, cujos resultados estão apresentados nas Figuras 7(a) a 7(f), a influência do custo da energia sobre a receita liquida é menor quando comparado com o período seco, sendo isto 


\section{ECONOMIA DE ENERGIA EM IRRIGAÇÃO POR PIVÔ CENTRAL EM FUNÇÃO} DA MELHORIA NA UNIFORMIDẢDE DA DISTRIBUIÇÃO DE ÁGUA

causado pelo menor custo da energia neste período do ano, e por ser no período úmido, tem-se uma redução no numero de irrigações, mas neste caso todos os custos avaliados são para irrigação total, portanto, os custos são unicamente causados pelo menor custo da energia que se tem por ser período úmido. Desse modo, o valor da receita liquida para CUC $=70 \%$ (Figura $7 a)$, varia de $R \$ 8.848,79 /$ ha a $R \$$ 4.632,68/ha (redução de 47,65\%) para preços de produto variando de $\mathrm{R} \$ 3,25 / \mathrm{kg}$ a $\mathrm{R} \$ 1,75 / \mathrm{kg}$.

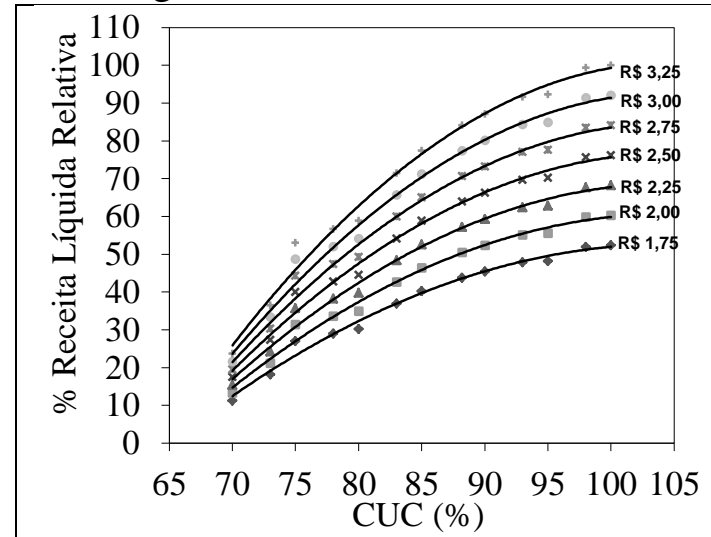

(a)

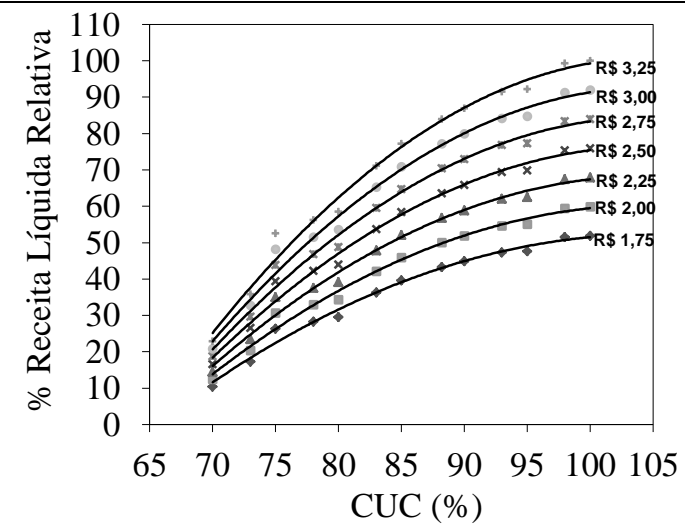

(c)

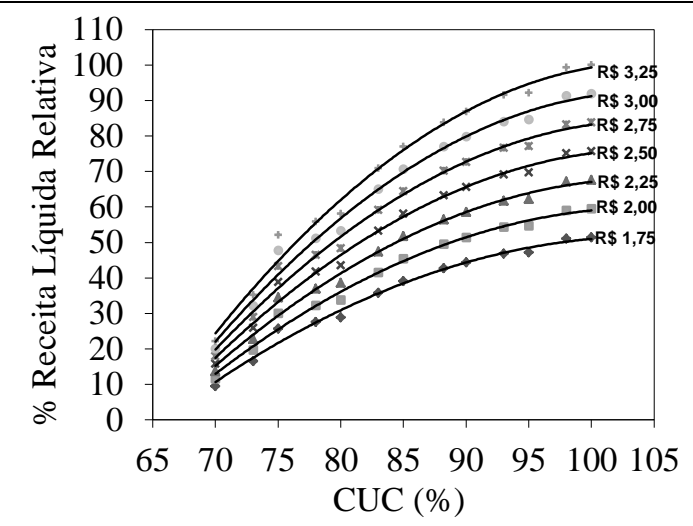

(e)
No CUC $=90 \%$, quando não se tem custo por consumo de água (Figura 7a), a receita liquida, para o preço do produto de $\mathrm{R} \$ 2,50 / \mathrm{kg}$, tem uma redução de $48,78 \%$ em relação ao preço de $\mathrm{R} \$ 1,75 / \mathrm{kg}$ no mesmo valor de CUC, significando uma redução de $\mathrm{R} \$ 4.316,21 / \mathrm{ha}$ ou $\mathrm{R} \$ 519.240,6$ para o total da área irrigada, se este valor é comparado com o período seco, no qual a redução, nas mesmas condições anteriormente mencionadas, é de $48,87 \%$.

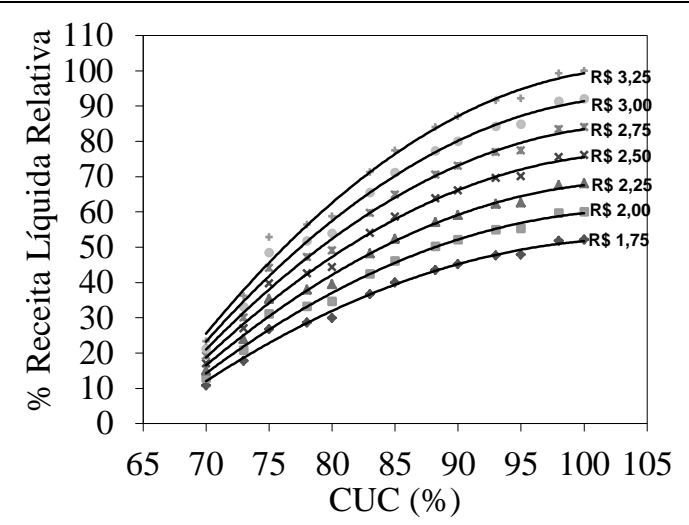

(b)

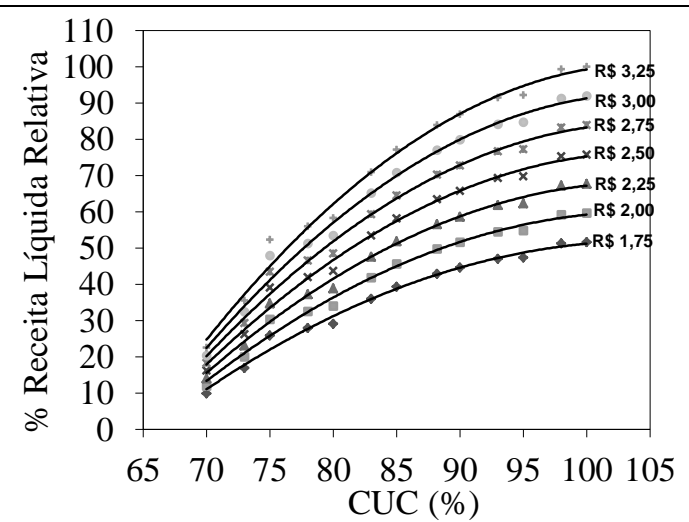

(d)

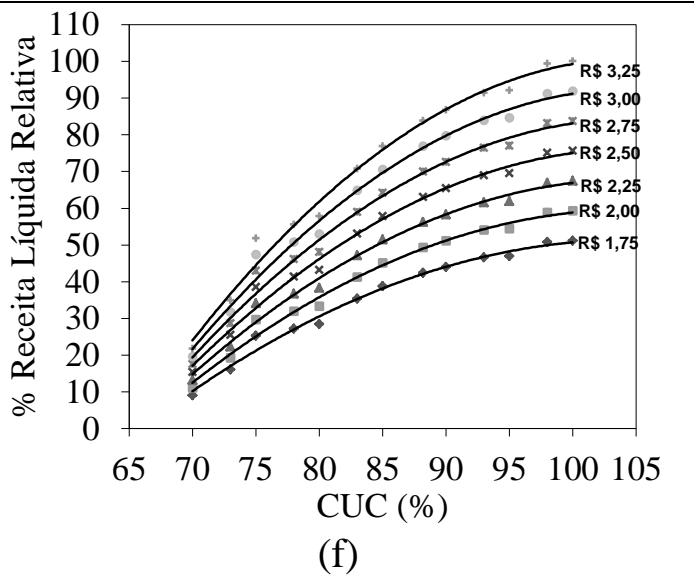

Rev. Bras. Agric. Irrigada v. 6, no . 3, p. 184 - 197 


\section{ECONOMIA DE ENERGIA EM IRRIGAÇÃO POR PIVÔ CENTRAL EM FUNÇÃO DA MELHORIA NA UNIFORMIDẢDE DA DISTRIBUIÇÃO DE ÁGUA}

Figura 7 - Receita líquida relativa (\%) em função do Coeficiente de Uniformidade de Christiansen (CUC), no período úmido, para seis preços da água

Se há tendências para a limitação da quantidade de água disponível para irrigar uma cultura, pode ser recomendável modificar os critérios uniformidade de distribuição de água pelos sistemas de irrigação (VON BERNUTH, 1983). Predeterminando um coeficiente de uniformidade mínimo pode não conseguir resultados ótimos no em termos de desenvolvimento da cultura e de rendimentos culturais, porém, o valor do coeficiente de uniformidade a ser utilizado pelo sistema de irrigação vai depender das condições locais e dos preços do produto.

Von Bernuth (1983) mostrou mediante um exemplo que quando a água é um fator limitante o coeficiente de uniformidade ótimo econômico pode ser menor que o coeficiente de uniformidade utilizado tradicionalmente (por exemplo, mínimo de 80\%) como ótimo para a produtividade das culturas. $\mathrm{O}$ mesmo autor relata que se a produção varia linearmente com a aplicação de água, ela depende

\section{CONCLUSÕES}

Considerando-se os dados obtidos nas simulações e as analises realizadas, pode se concluir que:

- A receita bruta proporcionada pelo cultivo do feijoeiro cresce com o aumento da uniformidade de distribuição de água uma vez que se obtêm maiores rendimentos de grãos. Para menores valores de CUC o preço do produto exerce menor influência sobre a receita bruta

- A influência da uniformidade de distribuição de água e do custo da água sobre a receita liquida é significativamente maior para os CUC- unicamente da lâmina média de água aplicada e não da uniformidade de aplicação. Isto é, se uma fração da área irrigada recebeu uma quantidade de água menor que a média, a outra fração da área, do mesmo tamanho, receberá uma quantidade maior de água, tanto quanto foi deixado de receber a outra fração da área, não afetando a produção total e sendo esta só afetada pela lâmina média de água aplicada.

Neste trabalho, a função de produção do feijoeiro utilizada foi do tipo quadrática, obtida por Saad (1996). Sendo assim, a produção em cada área que recebe uma quantidade de água inferior à lâmina média aplicada será inferior à produção média da cultura e, da mesma forma, a outra fração da área que recebe uma quantidade de água superior à média produzira uma quantidade maior, mas não igual ao déficit de produção da área menos irrigada. Portanto, quando a função de produção é quadrática, a produção depende tanto da lâmina média aplicada como da uniformidade de aplicação de água (VON BERNUTH, 1983).

's menores; da mesma forma, a receita liquida será mais afetada quando o custo do produto é menor, mantendo-se os custos por consumo de energia e por consumo da água.

- A variação nos benefícios econômicos, decorrentes da irrigação por pivô central na cultura do feijoeiro, considerando as produtividades alcançadas, simulando as lâminas de água aplicadas e mantendo-se a lâmina média, com diferentes uniformidades de distribuição de água e gastos com energia, são maiores quando a uniformidade de distribuição é maior, assim como aumenta quando o preço do produto aumenta. 


\section{ECONOMIA DE ENERGIA EM IRRIGAÇÃO POR PIVÔ CENTRAL EM FUNÇÃO DA MELHORIA NA UNIFORMIDẢDE DA DISTRIBUIÇÃO DE ÁGUA REFERÊNCIAS BIBLIOGRÁFICAS}

BRASIL, Agência Nacional De Energia Elétrica - ANEEL, resolução N. ${ }^{\circ}$ 456, de 29 de novembro de 2000, Publicado no Diário Oficial, 30 nov.2000, seção 1, p. 35, v. 138, n. 230-E. Condições Gerais de Fornecimento de Energia Elétrica.

CHRISTIANSEN, J.E. Irrigation by sprinkling. Berkeley: University of California, 1942. 124p. (Bulletin, 670)

FEINERMAN, E.; SHANI Y.; BRESLER E.; Economic optimization of sprinkler irrigation considering uncertainty of spatial water distribution. Australian Journal Agricultural Economics, Melbourne, v 3, p.88-107, 1989

FRIZZONE, J.A.; DOURADO NETO, D. Avaliação de sistemas de irrigação. In: MIRANDA, J.M. DE; PIRES, R.C. DE M (Org.). Irrigação. Jaboticabal: FUNEP, v. 2, p. 573-651, 2003.

HEERMANN, D.F.; HEIN, P.R. Performance characteristics of selfpropelled center-pivot sprinkler irrigation system. Transaction of the ASAE, St. Joseph, v. 11, n. 1, p.11-15, 1968.

IDE, M.R. Perfil da taxa de aplicação de água de duas instalações com pivô central. 1989, 80p. Dissertação (Mestrado na área de Irrigação e Drenagem) - Escola Superior de Agricultura "Luiz de Queiroz", Universidade de São Paulo, Piracicaba, 1989.

MAREK, T.U.; UNDERSANDER, D.J.; EBELING, L.L.; An areal weighted uniformity coefficient for center pivot irrigations systems. Transaction of the
ASAE, St. Joseph, v.29, n.6, p.1665-1667, 1986.

MARQUES, P.A. Modelo computacional para determinação do risco econômico em culturas irrigadas. 2005, 142 p. Tese (Doutorado na área de Irrigação e Drenagem) - Escola Superior de Agricultura "Luiz de Queiroz", Universidade de São Paulo, Piracicaba, 2005.

MARTINEZ Jr. F. e LAHOZ C. F. C., A cobrança pelo uso da água nas bacias hidrográficas do Piracicaba, Capivari e Jundiaí - aplicação e perspectivas. XVII Simpósio Brasileiro de Recursos Hídricos, São Paulo, 2007.

PROCON-SP, Equipe De Pesquisas DEP, PROCON-SP CONSTATA ALTA DE 0,24\% NA CESTA BÁSICA, São Paulo, 2009.

SAAD, A. O déficit de irrigação como estratégia de manejo da água em feijoeiro (Phaseolus vulgaris L.). 1996. 91p. Tese (Doutorado na área de Irrigação e Drenagem) - Escola Superior de Agricultura "Luiz de Queiroz", Universidade de São Paulo, Piracicaba, 1996.

VON BERNUTH, R.D. Uniformity design criteria under limited water. Transactions of the ASAE, Miami. v.26, n.5, p.14181421, 1983.

ZOCOLER, J.L; CESAR, L.E.V.; VANZELA, L.S. Efeito da linha lateral de um equipamento de irrigação tipo pivô central na uniformidade de distribuição de água e eficiência da irrigação. Engenharia na Agricultura, Viçosa, v. 12, n. 4, 290297, 2004. 